\title{
LA COOPERACIÓN INTERNACIONAL AL DESARROLLO ESPAÑOLA EN EL MARCO DE LA AGENDA 2030 PARA EL DESARROLLO SOSTENIBLE
}

Diana M. Verdiales López*

\section{Resumen}

La promulgación de la nueva Agenda para el Desarrollo Sostenible suscrita en el 2015 por la mayoría de los países en el mundo marcó el inicio de una segunda etapa para continuar trabajando en la construcción del desarrollo humano sostenible, enfocado principalmente en tres dimensiones claves: social, económico y medioambiental. Tras finalizar la implementación de los Objetivos de Desarrollo del Milenio (2000-2015) se vio la irremediable necesidad de continuar trabajando en la construcción de un mundo mejor, más equitativo, solidario y sostenible. Por ello, se desarrollaron 17 Objetivos de Desarrollo Sostenible (ODS) para que "nadie se quedara atrás". En este sentido, la Cooperación Internacional al Desarrollo española, si bien se vio afectada por la crisis económica de 2008, continúa trabajando para apoyar a aquellos países que más lo necesitan bajo proyectos de cooperación enfocados en las cuestiones relativas al medio ambiente, la diversidad cultural, el combate y erradicación de la pobreza y en las cuestiones relativas a la igualdad social y de género. Con la puesta en marcha de la Agenda 2030, España retoma su compromiso en materia de cooperación al desarrollo, sin embargo, las acciones desarrolladas hasta el momento, junto con las cuestiones económicas y sanitarias internacionales actuales, no le permiten ajustarse plenamente a los requerimientos contenidos en cada uno de los Objetivos de Desarrollo Sostenible.

Palabras clave: Cooperación al Desarrollo - Agenda 2030 - Objetivos de Desarrollo Sostenible - Cooperación Internacional al Desarrollo española

\section{SPANISH INTERNATIONAL DEVELOPMENT COOPERATION WITHIN THE FRAMEWORK OF THE 2030 AGENDA FOR SUSTAINABLE DEVELOPMENT}

\begin{abstract}
The promulgation of the new Agenda for Sustainable Development signed in 2015 by most countries in the world marked the beginning of a second stage to continue working on the construction of sustainable human development, focused on three key

\footnotetext{
* Doctora en Derechos Humanos, Paz y Desarrollo Sostenible (Universidad de Valencia). Responsable de Proyectos de Investigación y Cooperación del Centro de Estudios de Iberoamérica de la Universidad Rey Juan Carlos. Este trabajo se ha realizado en el marco del Grupo de Investigación de Alto Rendimiento en Libertad, Seguridad y Ciudadanía en el Orden Internacional (INTERCIVITAS), de la Universidad Rey Juan Carlos, del cual soy miembro. Correo electrónico: diana.verdiales@ urjc.es.

https://orcid.org/0000-0003-3275-2058
} 
dimensions: social, economic and environmental. After the completion of the implementation of the Millennium Development Goals (2000-2015) there was an irretrievable need to continue working on building a better, more equitable, supportive and sustainable world. That is why 17 Sustainable Development Goals (SDGs) were developed so that "no one was left behind". In this regard, the Spanish International Development Cooperation, while affected by the 2008 economic crisis, continues to work to support those countries that need it most under cooperation projects focused on environmental issues, cultural diversity, combating and eradicating poverty and on issues of social and gender equality. With the launch of the 2030 Agenda, Spain resumes its commitment to development cooperation, however, the actions developed so far together with current international economic and health issues do not allow it to fully comply with the requirements contained in each of the Sustainable Development Goals.

Keywords: Development cooperation - Agenda 2030 - Sustainable Development Goals - Spanish International Development Cooperation

TRABAJO RECIBIDO: 19/10/2020 - TRABAJO ACEPTADO: 21/11/2020 


\section{Introducción}

La Cooperación al Desarrollo tiene múltiples definiciones, según las necesidades y/o prioridades del propio desarrollo a través del tiempo. Podemos definirla como un conjunto de actuaciones internacionales para promover el desarrollo de los países que más lo necesitan, contribuyendo a la disminución y/o erradicación de la pobreza para promover un desarrollo humano más sostenible. Asimismo, el Comité de Ayuda al Desarrollo de la OCDE, define la Ayuda Oficial al Desarrollo (AOD) como "la ayuda gubernamental que promueve y respalda al desarrollo económico y el bienestar de los países en desarrollo" (Boni, 2010). Tradicionalmente la ayuda provenía de las aportaciones de los países desarrollados, sin embargo, en los últimos años las donaciones privadas (por empresas, asociaciones, fundaciones e individuos) se ha incrementado considerablemente. Lo que conllevó a la reformulación de los estándares de medición de la AOD, sobre todo tras la constitución de los Objetivos de Desarrollo Sostenible (ODS).

Los ODS incorporan en sus nuevas estrategias de desarrollo, además de los países tradicionalmente donantes, a los países receptores para que sean éstos los que contribuyan al logro de sus propios objetivos de desarrollo. Se introducen nuevos conceptos sobre los países receptores de ayuda, recalculando también el porcentaje para cada uno de ellos: $0.7 \%$ del Ingreso Nacional Bruto de la ayuda oficial al desarrollo AOD/INB para los países en desarrollo y entre 0.15 y el $0.20 \%$ para los países menos adelantados ${ }^{1}$.

En el caso de España, recordemos que en los años 50 era un país receptor de ayuda internacional al desarrollo y es en los años 70 cuando empieza a participar en el sistema de cooperación internacional al desarrollo como un país donante. Como podremos observar en las siguientes líneas, la Cooperación Internacional al Desarrollo Española (CIDE) ha participado activamente en las estrategias de cooperación internacional desde los años ochenta, mejorando progresivamente su sistema de gestión interna, así como su sistema de evaluación de programas y proyectos. Esto último ha posibilitado ampliar las zonas geográficas con las que tradicionalmente colaboraba, así como los sectores de actuación, destacando, en los últimos años, en la defensa y cuidados medioambientales, diversidad cultural y promoción de la igualdad de género.

El propósito de este análisis es comprender cómo se ha ido consolidado la cooperación internacional al desarrollo española en el marco de una nueva agenda global de desarrollo; destacando las acciones y estrategias para dar cumplimiento a los ODS y a sus compromisos en el marco de la cooperación internacional.

\footnotetext{
${ }^{1}$ Según la Organización de las Naciones Unidas son 47 los países en el mundo que se consideran "países menos adelantados" tomando en consideración su renta per cápita, el capital humano y la vulnerabilidad económica. Siendo éstos, según el informe de marzo del 20108, los siguientes: Afganistán, Angola, Bangladesh, Benin, Bhután, Burkina Faso, Burundi, Camboya, Chad, Comoras, Djibouti, Eritrea, Etiopía, Gambia, Guinea, Guinea-Bissau, Haití, Islas Salomón, Kiribati, Lesotho, Liberia, Madagascar, Malawi, Malí, Mauritania, Mozambique, Myanmar, Nepal, Níger, República Centroafricana, República Democrática del Congo, República Democrática Popular Lao, República Unida de Tanzanía, Rwanda, Santo Tomé y Príncipe, Senegal, Sierra Leona, Somalia, Sudán del Sur, Sudán, Timor-Leste, Togo, Tuvalu, Uganda Vanuatu, Yemen, Zambia
} 


\section{Origen y consolidación de la Cooperación Internacional al Desarrollo española.}

La Cooperación española al desarrollo ha sido, tradicionalmente, muy solidaria con las necesidades de los países que más lo requieren. Durante los años 50, era receptora de ayuda al desarrollo, incorporándose progresivamente a organismos internacionales en calidad de país donante. Siendo el año 1981 cuando España dejó de ser considerado como un país receptor de ayuda (Gómez, 2010).

A partir de los años ochenta la cooperación española al desarrollo fue tomando su curso hacia el camino de la solidaridad y el apoyo a los más desfavorecidos. En 1983, España solicitó salir de la lista de países receptores de Ayuda Oficial al Desarrollo (AOD) del Comité de Ayuda al Desarrollo (CAD) de la Organización de Cooperación y Desarrollo Económico (OCDE). A partir de ese año inicia sus primeras acciones en la cooperación internacional, creando en 1985 la Secretaria de Estado para la Cooperación Internacional y para Iberoamérica (SECIPI) como el primer órgano político especializado en cooperación al desarrollo, responsable de la dirección, programación, control y evaluación de la política española de cooperación al desarrollo (Gómez, 2010).

En este sentido, la Cooperación Internacional al Desarrollo española ha tenido varias etapas desde su constitución hasta su actual consolidación, entre las que destacamos a continuación:

1.-Etapa de constitución de la Cooperación Internacional al Desarrollo española. Durante la década de los ochenta y principios de los noventa, fueron constituyéndose las principales instituciones y programas de cooperación al desarrollo, tanto a nivel nacional como a nivel autonómico y regional, debido al destacado papel que empezaron a realizar las administraciones locales y autonómicas en la cooperación descentralizada española.

Con su incorporación a la Unión Europea, en 1986, España empieza a fortalecer sus instituciones sociales y económicas, favoreciendo la posibilidad de contar con mayores recursos para la cooperación internacional. Por lo que, podemos considerar este periodo como la etapa de constitución de la Cooperación Internacional al Desarrollo en España.

A finales de 1988, se crearon tanto la Agencia Española de Cooperación Internacional (AECI) adscrita a la SECIPI, con el objetivo de impulsar la política de cooperación internacional española; como la Oficina de Planificación y Evaluación (OPE) del Gobierno de España para apoyar las estrategias de cooperación internacional.

\section{2.-Etapa de consolidación de la Cooperación Internacional al Desarrollo} española. Este período coincide con la incorporación de España en el Comité de Ayuda al Desarrollo (CAD) en 1991 así como con la creación, en 1995 en Extremadura, del Consejo Asesor de Cooperación Internacional para el Desarrollo, como órgano encargado de regular las ayudas al tercer mundo en materia de cooperación para el desarrollo.

Si bien durante los años ochenta se llevaron a cabo diversas manifestaciones por parte de la sociedad civil para demandar mayor participación en el ámbito de la cooperación internacional, mediante la participación activa de las Organizaciones No Gubernamentales para el Desarrollo (ONGD), no fue hasta 1994 cuando se registraron mayores y más numerosas manifestaciones sociales para demandar una mejora en la 
calidad de la cooperación, así como un incremento de la AOD hasta alcanzar el $0.7 \%$. Dichas demandas sociales dieron como resultado la firma del "Pacto por la solidaridad" el cual dejaba de manifiesto el compromiso parlamentario para incrementar la AOD hasta aproximarse al mencionado porcentaje, así como la creación del Consejo de Cooperación para el Desarrollo (1995) con el objetivo de facilitar el diálogo entre la administración pública, las ONGD y los agentes sociales (Gómez, 2010).

Por otro lado, y tras evaluar los resultados obtenidos en el primer examen de pares $^{2}$ del CAD en 1994, se determinó que la planificación de la cooperación española orientada a resultados era insuficiente, que no existía un sistema de seguimiento integral y que la cultura y práctica de la evaluación era muy débil. Por ello, el gobierno de España inició una serie de acciones encaminadas a mejorar la calidad, el rigor, la transparencia y la eficacia de la cooperación española a los fines de dar respuesta a las observaciones obtenidas en dicha evaluación. Prueba de ello fue la construcción de un sistema de evaluación mediante el fortalecimiento de los recursos humanos de la OPE; el establecimiento de un presupuesto específico para la financiación de las evaluaciones; el refuerzo de la participación en eventos internacionales sobre evaluación, tales como redes y foros multilaterales en el ámbito del CAD y la Unión Europea; y sobre todo la elaboración de una Metodología de Evaluación de la Cooperación Española en 1998 así como la elaboración de un plan de evaluaciones durante ese mismo año emitiendo cuatro evaluaciones (Arguilés, 2014).

Siguiendo esta línea se promulgó, en 1998, la Ley de Cooperación Internacional para el Desarrollo bajo el Real Decreto 23/1998, cuyo propósito básico, contenido en el Artículo 1 es impulsar "procesos de desarrollo que atiendan a la defensa y protección de los Derechos Humanos y las libertades fundamentales, las necesidades de bienestar económico y social, la sostenibilidad y regeneración del medio ambiente, en los países que tienen elevados niveles de pobreza y en aquellos que se encuentran en transición hacia la plena consolidación de sus instituciones democráticas y su inserción en la económica internacional" (BOE, 1998). Dicha ley enfatiza que "la política de cooperación internacional para el desarrollo responde específicamente al mandato contenido en el preámbulo de la Constitución Española de contribuir en el fortalecimiento de unas relaciones pacíficas y de eficaz cooperación entre todos los pueblos de la Tierra" (Real Decreto 23, 1998). Asimismo, describe las modalidades bajo las cuales pueden financiarse los programas de cooperación al desarrollo, clasificándolos en bilaterales y multilaterales.

Por tanto, en la mencionada Ley se señalan los diversos órganos rectores que representan la estructura institucional de la cooperación al desarrollo, siendo éstos los siguientes: Ministerio de Asuntos Exteriores y de Cooperación, la Secretaría de Estado de Cooperación Internacional, la Agencia Española de Cooperación Internacional para el Desarrollo (AECID), el Consejo de Cooperación al Desarrollo, la Comisión Interterritorial de Cooperación para el Desarrollo, la Comisión Interministerial de Cooperación Internacional, el Consejo de Política Exterior y la Comisión Interministerial para Coordinar Planes de Ayuda Humanitaria al Exterior.

A pesar de los recién mencionados avances, a finales de los años noventa, se registró un ligero retroceso en la contribución española al desarrollo producto del

\footnotetext{
${ }^{2}$ Los exámenes de pares del CAD de la OCDE se llevan a cabo cada 4 años para evaluar la actuación del país miembro, valorando tanto la política de cooperación como su implementación.
} 
estancamiento económico. Bajo esta situación se hizo más evidente la escasez de una cultura y práctica de evaluación de la Cooperación al Desarrollo española, así como la necesidad de implementar un Sistema de Evaluación orientado al aprendizaje en las ONGD.

3.-Etapa de expansión y modernización de la Cooperación Internacional al Desarrollo española. A principios del siglo XXI, el gobierno español realiza un gran esfuerzo por la expansión y modernización de los planes e instrumentos en materia de Cooperación Internacional al Desarrollo. En ese sentido se crean directrices nacionales bajo estrategias sectoriales regidas por el primer Plan Director de la Cooperación para el Desarrollo en 2001. De tal forma que dicha modernización, sumada al crecimiento económico sostenido, hizo posible que la participación de España en materia de Cooperación Internacional al Desarrollo se incrementara y se mantuviera estable durante la primera década del siglo XXI, jugando un papel importante en la cooperación multilateral.

Eso supuso un incremento considerable en los recursos destinados por el gobierno español para la cooperación al desarrollo hacia América Latina, pasando de 365 millones de dólares a cerca de 660 millones entre el periodo comprendido entre el 2002 y el 2006, situando a España solo por detrás de Estados Unidos en donaciones en la región. En 2007, la cooperación española logró superar los recursos destinados por Estados Unidos a la cooperación al desarrollo, alcanzando un aporte del 23\% de la AOD en la región latinoamericana (Colacrai, 2010).

Parte de las acciones realizadas por el gobierno español para impulsar la política de Cooperación Internacional al Desarrollo fue la modificación, en el 2004, de la estructura orgánica básica del Ministerio de Asuntos Exteriores y de Cooperación, sustituyendo la Oficina de Planificación y Evaluación por la Subdirección General de Planificación y Evaluación de Políticas de Desarrollo. Un año más tarde, en el 2005, y dada su importancia en materia de planificación y evaluación, dicha Subdirección fue elevada de rango a Dirección General de Planificación y Evaluación de Políticas para el Desarrollo (DGPOLDE).

La necesidad de España de trabajar hacia la eficacia de la Ayuda al Desarrollo manifiesta en la primera década del siglo XXI, no sólo fue una prioridad nacional, sino que respondió a una preocupación global en materia de desarrollo. Ya que, pese a las recomendaciones internacionales del CAD de mantener el porcentaje de la AOD/INB a un $0,7 \%$, ésta había alcanzado un mínimo histórico del $0.14 \%$ en el 2014 (OXFAM y UNICEF, 2015). De ahí la necesidad de trabajar en la eficacia de la ayuda al desarrollo, incorporando mecanismos de evaluación y bajo las directrices señaladas tanto en la Declaración del Milenio (2000) y en la Declaración de París (2005), como parte de los compromisos adquiridos a nivel internacional.

Sin embargo, durante la primera década del siglo XXI la Cooperación al Desarrollo española sufrió un duro revés. Como hemos observado anteriormente durante los años 2004 al 2008 fueron buenos para la cooperación española, superando a Estados Unidos en porcentaje de la RNB destinada a la AOD. Es con la crisis del 2008 cuando el presupuesto de la cooperación española sufre una reducción del $70 \%{ }^{3}$ (OXFAM y UNICEF, 2015). Aunque la caída más abrupta se registró entre el 2011 y el 2015, es

\footnotetext{
${ }^{3}$ En el caso de los Fondos para la Ayuda Humanitaria, el presupuesto se redujo hasta un $82 \%$ entre el 2009 y el 2014 , pasando de 319 millones de euros a 57 millones de euros.
} 
necesario precisar que el descenso de la AOD española inició con la recesión económica internacional en el 2008.

A pesar de que fue una crisis económica internacional, España fue uno de los países que más disminuyó su presupuesto a la AOD. Países como Portugal, Irlanda o Reino Unido que también se vieron afectados severamente por la crisis, no disminuyeron tanto el porcentaje de la AOD como lo hizo de España. Por lo contrario, países como el Reino Unido aumentaron su contribución alcanzando el 0.7\% (OCDE, 2018).

\section{PAÍSES DONDE LA AOD COMO PORCENTAJE DE LA RNB HA DISMINUIDO SIGNIFICATIVAMENTE}

\begin{tabular}{llc}
\hline & From & Level in 2017 \\
\hline Australia & $0.34 \%$ in 2011 & $0.23 \%$ \\
Austria & $0.50 \%$ in 2007 & $0.30 \%$ \\
Canada & $0.34 \%$ in 2010 & $0.26 \%$ \\
Denmark & $0.91 \%$ in 2010 & $0.72 \%$ \\
Ireland & $0.59 \%$ in 2008 & $0.30 \%$ \\
Netherlands & $0.82 \%$ in 2009 & $0.60 \%$ \\
New Zealand & $0.30 \%$ in 2008 & $0.23 \%$ \\
Portugal & $0.31 \%$ in 2011 & $0.18 \%$ \\
Spain & $0.46 \%$ in 2009 & $0.19 \%$ \\
\hline
\end{tabular}

Fuente: OCDE (2018) Informe de Cooperación al Desarrollo

Una vez recuperada económicamente, España retomó su compromiso con la cooperación internacional para el desarrollo, incrementando hasta un 7,4\% (equivalente a 2.586,56 millones de euros) de su AOD en 2019 con respecto al año anterior. Siendo la región Latinoamérica la receptora de la mayor parte de la AOD, seguida de África. Los principales proyectos de cooperación española para el desarrollo en la región Latinoamérica fueron de carácter triangular, fomentando la cooperación entre los países de la región (Colacrai, 2010).

\section{La Cooperación Española al Desarrollo y los Objetivos de Desarrollo Sostenible}

Una vez concluido el período de implementación de los Objetivos de Desarrollo del Milenio, ODM (2000-2015), la comunidad internacional observó con preocupación que los resultados obtenidos en la mayoría de los países menos desarrollados presentaban grandes claroscuros, existiendo grandes disparidades entre los países desarrollados y en vías de desarrollo. Positivamente se observó que la pobreza extrema se había reducido a la mitad y seguía una tendencia a la baja (CEPAL, 2016); que se había aumentado considerablemente el número de personas con acceso de agua potable; que había mejoras considerables en la reducción de los índices de mortalidad infantil y un aumento igualmente considerable de niños que asistían a las escuelas primarias. Sin embargo, también observaron con preocupación cómo aspectos como la salud materna y reproductiva continuaban siendo un importante problema, la desigualdad de género y todo lo relativo a los temas medioambientales (CEPAL, 2016).

Dado que no se obtuvieron los resultados esperados tras la implementación de los ODM, se decidió por unanimidad continuar trabajando en la construcción de una agenda de trabajo más amplia que incluyera las nuevas problemáticas que afectan a la 
sociedad internacional actual. Fue por lo que se celebró en julio de 2015 la III Conferencia de Financiación del Desarrollo en Addis Abeba, para poner de manifiesto las posibles acciones que contribuyeran a mejorar la financiación de los programas al desarrollo. Dicha Conferencia impulsó la puesta en marcha de la nueva Agenda para el Desarrollo.

La nueva Agenda para el de Desarrollo Sostenible ${ }^{4}$ se creó con el objetivo de continuar avanzando hacia la construcción de un mundo más equitativo, incluyente e igualitario. La nueva Agenda (denominada Agenda 2030), se constituye de 17 ODS y 169 metas asociadas a dichos Objetivos a ser alcanzados en 2030, abarcando las dimensiones sociales, económicas y medioambientales, en todos los países, tanto desarrollados como en vías de desarrollo.

A finales del 2008 e inicios del 2009, España se vio inmersa en una crisis económica que le llevó a tomar medidas de ajuste presupuestario afectando severamente su Estado de bienestar. Esto dificultó el cumplimiento de la última fase de implementación de los ODM, ya que fue uno de los países de la OCDE con altos índices de desigualdad, aumentando considerablemente el número de personas en estado de pobreza y vulnerabilidad ${ }^{5}$, debido a la reducción de las prestaciones en salud, educación y, principalmente, a la alta tasa de desempleo.

Pese a ello, el gobierno español ha diseñado, en 2019, un Plan de Acción para la implementación de la Agenda 2030, en el cual se hace un balance sobre los resultados e indicadores de cada ODS para impulsar el desarrollo de las mismas de forma transversal con las políticas públicas del país. Entre las áreas prioritarias para la cooperación internacional al desarrollo española se señalan las siguientes: la erradicación de la pobreza; la disminución de las desigualdades; la sostenibilidad en todas sus dimensiones; el enfoque basado en Derechos Humanos, la persona, como sujeto de derechos; y el enfoque de Género.

Pese a la activa participación que está teniendo España en los foros internacionales, su aporte en la Cooperación Internacional al Desarrollo continúa siendo deficiente. Ya que, en el año 2016, un año posterior a su adhesión a la Agenda 2030, España destinaba un $0,12 \%$ de AOD de su Renta Nacional Bruta (RNB), muy lejana al $0.4 \%$ de la meta que se propuso alcanzar para 2019 (OXFAM y UNICEF, 2015). Aunque del Gobierno de Español había aumentado el presupuesto de AOD, como vemos no se logró el objetivo antes mencionado. Por otra parte, se observó que durante el periodo 2018 al 2020 no hubo ningún incremento en la AOD destinada por España, manteniendo el presupuesto en las mismas cifras durante esos dos años (Cascante, 2020). Por lo que dicha situación podría terminar afectando los compromisos españoles adquiridos con los terceros países en materia de cooperación al desarrollo.

\footnotetext{
${ }^{4}$ Es necesario señalar que las bases para la construcción de la nueva Agenda 2030 para el Desarrollo sostenible, además de la Carta de Naciones Unidas y la Declaración Universal de los Derechos Humanos, fueron los tratados internacionales de Derechos humanos, la Declaración del Milenio, el documento final de la Cumbre Mundial 2005, la Declaración sobre el Derecho al Desarrollo, la Declaración de Rio sobre el Medio Ambiente y el Desarrollo, la Cumbre Mundial sobre el Desarrollo Sostenible, la Cumbre Mundial sobre Desarrollo Social, el Programa de Acción de la Conferencia Internacional sobre la Población y el Desarrollo, la Plataforma de Acción de Beijing y la Conferencia de las Naciones Unidas sobre el Desarrollo Sostenible. AGNU, Asamblea General de Naciones Unidas. (2015). Resolución aprobada por la Asamblea General el 25 de septiembre de 2015: Transformar nuestro mundo: la Agenda 2030 para el desarrollo. A/RES/70/1, Septuagésimo período de sesiones. Nueva York, Estados Unidos. p. 4-5.

${ }^{5}$ La cifra de personas en estado de pobreza y vulnerabilidad ascendió al 29,2\% en 2014, equivalente a 13,4 millones de personas ( 2,3 millones más que en 2008 y 6 puntos porcentuales más que la media europea).
} 
Para avanzar en ese sentido y dar cumplimiento a la implementación de la Agenda de Desarrollo Sostenible 2030, España creó en 2017, la figura de Embajador en Misión Especial para la Agenda 2030, mediante Consejo de Ministros. Durante este mismo año, se aprobaron dos proposiciones de Ley (PNL) para la implementación de la Agenda en España. A mediados de ese mismo año, se creó un Grupo de Alto Nivel (GAN) como el grupo de trabajo encargado de articular a todos los ministerios con el objetivo de coordinar la posición española ante los ODS. Asimismo, se realizó una propuesta de estudio para la definición de la Estrategia española con el objetivo de alcanzar los ODS. Hasta el 2017, 6 de las 17 comunidades autónomas (más 2 ciudades autónomas: Ceuta y Melilla) y 8 ayuntamientos habían tomado medidas para iniciar el proceso de inclusión de sus políticas en consonancia con los ODS. En julio de 2018, España participó en el Foro Político de Alto Nivel 2018, presentándose voluntario para el Examen Nacional $(\mathrm{ENV})^{6}$ sobre los avances del país en lo relativo a los ODS. En este sentido se tiene programado trabajar en lo acordado en el Plan de Acción 2018-2020, para poder presentarse nuevamente a los ENV en el 2020, 2025 y 2030. Finalmente, el 19 de junio de 2018, se creó la figura del Alto Comisionado para la Agencia 2030, como el encargado de coordinar las actuaciones de todos los actores nacionales interesados en el logro de los ODS.

Es necesario precisar que, hasta la fecha, España no ha conseguido los resultados esperados en la primera fase de implementación. La media de acciones realizadas por ODS por el gobierno español es de 30. Siendo 12 la que menos tiene (ODS 7) y 49 la que más (ODS 16). De los 17 ODS, España consigue dar un ligero cumplimiento en algunas metas de 8 de ellos ${ }^{7}$.

Asimismo, la implicación de España en la cooperación internacional al desarrollo recae en los compromisos internacionales adquiridos en la adhesión al Comité de Ayuda al Desarrollo (CAD) de la Organización para la Cooperación y el Desarrollo de la Economía (OCDE); con la Agenda de Eficacia de la Ayuda, de la Declaración de París, así como de los consensos europeos hechos en la materia (Cascante, 2020).

Aunque todavía es pronto para hacer un balance de los resultados hacia el cumplimiento de la Agenda 2030, podemos decir que hasta el momento las metas a corto plazo no están teniendo los resultados esperados. Y eso puede generar un retraso en el cumplimiento a mediano y largo plazo de los mismos.

Es por ello que diversas organizaciones de la sociedad civil continúan demandando una mayor participación por parte del gobierno español para dar cumplimiento a los objetivos y metas señalados en la Agenda 2030. Organizaciones como Intermón Oxfam y Unicef España señalan que, para que España tenga un papel relevante en la contribución de la universalidad de dicha Agenda, se requiere avanzar por lo menos en cinco ámbitos de acción pública, que son: asegurar las posibilidades de recaudación

\footnotetext{
${ }^{6}$ El Examen Nacional Voluntario, propuesto por Naciones Unidas, es un mecanismo de seguimiento y revisión de las estrategias de implementación de los ODS en las políticas nacionales. Mayor información: https://www.ohchr.org/sp/Issues/SDGS/Pages/2020VoluntaryNationalReviews.aspx

${ }^{7}$ De los 17 ODS España presenta una tendencia favorable en algunas metas de 8 de éstos $(2,3,4,10,12$, 14, y 15). OXFAM Intermón y UNICEF Comité Español (2017), “Agenda 2030. Una oportunidad para las personas y el planeta”, Madrid, España, pp.12-15. Los porcentajes de cobertura por ODS por parte de España son los siguientes: ODS 1, 6\%; ODS 2, 3\%: ODS 3, 5\%; ODS 4, 5\%; ODS 5, 9\%; ODS 6, 5\%; ODS 7, $2 \%$; ODS 8, 7\%; ODS 9, 6\%; ODS 10, 4\%; ODS 11, 6\%; ODS 12, 7\%; ODS 13, 4\%; ODS 14, 7\%; ODS 15, 7\%; ODS 16, 10\% y ODS 17, 8\%. GOBIERNO DE ESPAÑA (2018), "Informe de España para el Examen Nacional Voluntario 2018”. Gobierno de España, Madrid, p. 96.
} 
progresiva del sistema fiscal; comprometerse con las iniciativas de promoción de la cooperación fiscal internacional; implicar a todos los agentes privados para favorecer un crecimiento más incluyente; apoyar a los países en desarrollo en materia de ciencia, tecnología, innovación y desarrollo para contribuir activamente a los esfuerzos internacionales de inversión en $\mathrm{I}+\mathrm{D}+\mathrm{i}$; y participar activamente para atender a los llamados problemas sistémicos.

En ese sentido, el Plan de Acción para la implementación de la Agenda 2030 en España describe las acciones concretas que se pretenden desarrollar para avanzar hacia el cumplimiento de los ODS. Dichas acciones se enmarcan en una serie de políticas palanca ${ }^{8}$ o áreas prioritarias que han sido identificadas por el gobierno español, para coordinar transversalmente las acciones orientadas hacia el logro de los ODS. Siendo éstas las siguientes:

\section{Cooperación Internacional al Desarrollo Española y los ODS.}

Áreas prioritarias de Actuación

\begin{tabular}{|c|c|}
\hline $\begin{array}{c}\text { Área Prioritaria/ Política } \\
\text { Palanca } \\
\end{array}$ & Propuesta \\
\hline $\begin{array}{l}\quad 1 . \quad \text { Prevención } \\
\text { y lucha contra la pobreza, la } \\
\text { desigualdad y la exclusión } \\
\text { social. }\end{array}$ & $\begin{array}{l}\bullet \text { Luchar contra la pobreza y la desigualdad, } \\
\text { especialmente la pobreza severa y la pobreza infantil. } \\
\bullet \quad \text { Invertir en personas, centrándose en la } \\
\text { educación inclusiva y promoviendo un empleo adecuado. }\end{array}$ \\
\hline 10 у 11 ODS: $1,2,3,4,5$, & $\begin{array}{l}\text { - Mejorar la protección social a través de } \\
\text { servicios adecuados de vivienda, sanidad, atención a las } \\
\text { personas dependientes, servicios sociales suficientes y } \\
\text { mantenimiento de un sistema de prestaciones sociales que eviten } \\
\text { situaciones de necesidad. }\end{array}$ \\
\hline \begin{tabular}{lr}
\multicolumn{1}{c}{2.} & Igualdad de \\
oportunidades: & Plan \\
Estratégico. &
\end{tabular} & $\begin{array}{l}\bullet \quad \text { Elaboración del próximo Plan Estratégico de } \\
\text { Igualdad de Oportunidades (PEIO) tomando en consideración } \\
\text { los objetivos y metas señalados en el Objetivo } 5 \text { de la Agenda } \\
2030 \text {. }\end{array}$ \\
\hline ODS: $1,4,5,8,16$ & \\
\hline
\end{tabular}

\footnotetext{
${ }^{8}$ Se entiende por políticas palanca a "los programas o políticas con capacidad de impulsar un desarrollo sostenible coherente y sostenido, así como de acelerar el proceso de implementación de los ODS con mayor impacto y rapidez. GOBIERNO DE ESPAÑA (2018), "Informe de España para el Examen Nacional Voluntario 2018”. Gobierno de España, Madrid, p. 106.
} 


\begin{tabular}{|c|c|}
\hline $\begin{array}{c}\text { 3. La Agenda } \\
\text { urbana española }\end{array}$ & 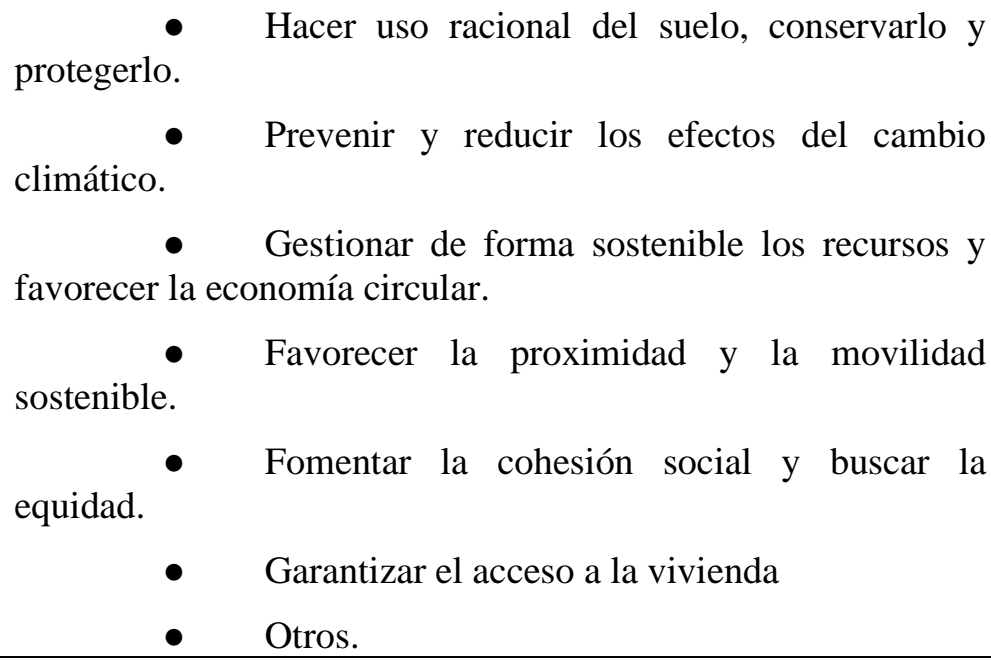 \\
\hline $\begin{array}{l}\text { ODS: } 5,7,8,12 \text {, } \\
13,14 \text { y } 15 \text {. }\end{array}$ & $\begin{array}{l}\text { • Avanzar en la implementación de un modelo de } \\
\text { desarrollo y crecimiento que permita optimizar la utilización de } \\
\text { los recursos, materiales y productos disponibles. } \\
\text { • Preservar y mejorar el capital natural mediante } \\
\text { la selección de los recursos y sistemas renovables o los de } \\
\text { mejores resultados. } \\
\text { - Fomentar la eficacia de los sistemas. } \\
\text { - Generar nuevas capacidades y nuevos puestos } \\
\text { de trabajo. } \\
\text { biodiversidad y los ecosistemas. }\end{array}$ \\
\hline $\begin{array}{l}\text { 5. La Ley de } \\
\text { Cambio }{ }^{\text {Climático }} \mathrm{y} \\
\text { Transición Energética. }\end{array}$ & $\begin{array}{l}\bullet \quad \text { Asegurar la neutralidad de las emisiones de } \\
\text { gases de efecto invernadero y un sistema energético eficiente y } \\
\text { renovable en España para } 2050 \text {. } \\
\text { - Anticipar el conocimiento de posibles efectos } \\
\text { del cambio climático en España y facilitar la resiliencia y } \\
\text { adaptación frente a los mismos. } \\
\bullet \quad \text { Garantizar la cohesión social y territorial en un } \\
\text { contexto de la seguridad energética. }\end{array}$ \\
\hline $\begin{array}{l}\quad 6 . \quad \text { La } \\
\text { Investigación Científica y } \\
\text { Técnica para los ODS. }\end{array}$ & $\begin{array}{l}\text { - Generación de conocimiento en todos los } \\
\text { ámbitos. } \\
\text { científico-técnicas y de innovación incluidas en cada uno de los } \\
\text { RETOS. } \\
\text { - Coordinación con las políticas y estrategias } \\
\text { sectoriales de ámbito estatal durante los próximos años. } \\
\text { C Contribución universal de la I+D+I a la } \\
\text { consecución de los ODS. }\end{array}$ \\
\hline $\begin{array}{l}\quad 7 . \quad \text { La } \\
\text { Economía Social: Estrategia } \\
2017-2020 .\end{array}$ & $\begin{array}{l}\text { • Apoyo al empleo y emprendimiento de la } \\
\text { economía social. } \\
\text { • Impulso a la consolidación de empresas de la }\end{array}$ \\
\hline
\end{tabular}




\begin{tabular}{|c|c|}
\hline ODS: $5,8,9,10 \mathrm{y}$ & $\begin{array}{l}\text { Economía Social. } \\
\bullet \quad \text { Impulso de la Economía Digital en las } \\
\text { entidades de Economía Social. } \\
\text { de la Agenda internacional (Iberoamérica, Europa y } \\
\text { mediterráneo). } \\
\bullet \quad \text { Fomento de la igualdad de género y de la } \\
\text { inclusión social en la economía social. }\end{array}$ \\
\hline $\begin{array}{c}8 . \quad \text { Plan } \\
\text { Gobierno Abierto. }\end{array}$ & $\begin{array}{l}\text { • Configurar un nuevo marco de gobernanza } \\
\text { pública y una renovada arquitectura estatal. } \\
\bullet \quad \text { Transparencia, participación y rendición de } \\
\text { cuentas como eje básico de toda acción política. } \\
\bullet \quad \text { Compromiso por mantener los valores } \\
\text { promovidos por la Alianza de gobierno Abierto (Open } \\
\text { Goverment Partnership) de la que España es participe. }\end{array}$ \\
\hline $\begin{array}{l}9 . \quad \text { Recuperar } \\
\text { la Cooperación Española al } \\
\text { servicio de los ODS. }\end{array}$ & $\begin{array}{l}\text { • Favorecer el logro de los ODS y contribuir a la } \\
\text { erradicación de la pobreza. } \\
\text { • Construir las resiliencias de las personas y } \\
\text { comunidades. } \\
\bullet \quad \text { Promover un crecimiento económico inclusivo. } \\
\bullet \quad \text { Conservación del planeta y lucha contra el } \\
\text { cambio climático. } \\
\text { C Construcción y fortalecimiento de alianzas o } \\
\text { asociaciones con los diferentes actores comprometidos con el } \\
\text { alcance de los ODS. }\end{array}$ \\
\hline
\end{tabular}

Fuente: Elaboración propia con información obtenida en GOBIERNO DE ESPAÑA (2018), "Informe de España para el Examen Nacional Voluntario 2018". Gobierno de España, Madrid, p. 108-117.

De las 9 áreas prioritarias de actuación de la cooperación española para el desarrollo y los ODS, podemos observar como la política palanca número 9 se basa más en acciones concretas para generar desarrollo sostenible en el exterior. En ella se requiere de acciones conjuntas para contribuir a la erradicación de la pobreza y fortalecer el logro de los ODS; apoyar acciones concretas para construir comunidades más resilientes; promover el desarrollo económico inclusivo en las comunidades donde más se requiera; promover la conservación del planeta y el fomento de la implementación de acción contra el cambio climático así como la construcción y fortalecimiento de alianzas con los diferentes actores nacionales e internacionales socialmente comprometidos para el logro de los ODS.

Para continuar trabajando en la implementación de las políticas palanca antes mencionadas y poder avanzar hacia el cumplimiento de los ODS se elevó el rango institucional de las dependencias gubernamentales relativas a la Agenda 2030. Por lo que el Alto Comisionado para la Agenda 2030, organismo encargado de llevar a cabo la implementación de los ODS en las políticas públicas del Estado, pasó a convertirse, en enero de 2020, en una Secretaría de Estado para la Agenda 2030, cuyo objetivo es 
continuar trabajando en las de acciones impulso, seguimiento y cooperación entre los diferentes niveles de gobierno para el logro de los ODS. Estas acciones han sido vistas muy positivamente tanto por la población española como por los partidos políticos de la oposición. Sin embargo, al encontrarse dicha Secretaría dentro del Ministerio de Derechos Sociales y Agenda 2030, se corre el riesgo de que las acciones contenidas en la Agenda 2030 se promuevan más internamente que en programas externos de cooperación, reforzando más un compromiso y vocación social nacional que un compromiso social universal. Cuestión factible si se toma en consideración que la estructura social española quedó muy debilitada o "quebrado" según palabras de Philip Alson, Relator de Naciones Unidas para la Pobreza y los Derechos Humanos (Cascante, 2020).

Este cambio dentro de la estructura del gobierno español señala el compromiso que tiene el país hacia el cumplimiento de los ODS. La AECID basa sus acciones y compromisos internacionales en el V Plan de Director de la Cooperación Española, poniendo énfasis en la incorporación del enfoque basado en los derechos humanos, en el enfoque de género y en las cuestiones relativas al cuidado medioambiental y en la diversidad cultural como parte de su compromiso con la Agenda 2030 para el desarrollo sostenible.

Según Nieves Lagares, se han planteado 3 planos sobre la mejora de la calidad y eficacia de la ayuda española para el desarrollo dentro de la agenda de desarrollo, los cuales serían los siguientes:

a) En el estratégico: desde el que se han abordado los problemas sobre la asignación de la ayuda, la articulación de los donantes con las estrategias nacionales y el apoyo directo a los presupuestos de los países en desarrollo.

b) En el nivel de instrumentos y procesos: los temas giraban en torno a la calidad de la ayuda, la desvinculación de la ayuda y la armonización de las políticas, los procedimientos y las prácticas de los donantes.

c) En el ámbito de la práctica sobre el terreno: el asunto fundamental se circunscribe a la coordinación entre donantes (Lagares, 2011).

Según esta autora las encuestas de opinión en España son favorables a la implementación de acciones relacionadas con la cooperación para el desarrollo, siguiendo la línea de lo establecido tanto en los ODM como en los actuales ODS sobre las actuaciones para erradicación de la pobreza y generar desarrollo en los países menos adelantados.

El contar con el apoyo de la población española constituye un elemento clave para que el gobierno español mejore sus acciones en la cooperación internacional para el desarrollo, promoviendo programas más eficientes e innovadores que incorporan al menos el enfoque basado en los derechos humanos para contribuir de una forma más integral las acciones destinadas para en la cooperación internacional para el desarrollo sostenible.

\section{Conclusiones}

La importancia de trabajar para contribuir a la mejora del desarrollo humano sostenible es una idea que se gestó con la promulgación de la Declaración de los Objetivos del Milenio y posteriormente se reforzó con la creación de la Agenda 2030 para el 
desarrollo sostenible. Los nuevos ODS pretenden trabajar conjuntamente para que nadie se quede atrás, incorporando como ejes centrales al planeta, las personas, la prosperidad, la paz y las alianzas entre los países. La idea del legado del anterior Secretario General de las Naciones Unidas, Ban Ki-Moon, de continuar trabajando por un desarrollo más equitativo y sostenible en todos los países del mundo, bajo la implementación de la Agenda 2030, interpela a todos los Estados tanto desarrollados como en vías de desarrollo. La Agenda 2030 constituye un hito en la historia del desarrollo, al presentarse como un proyecto global que pretende evitar disparidades entre los países. En este sentido, todos los Estados miembros se ven comprometidos a incorporar los ODS en sus agendas nacionales, mejorando y/o reforzando con ello el bienestar de su población.

En el caso de España, el trabajo legislativo realizado en los últimos años en materia de cooperación al desarrollo, constituye un elemento clave para la realización de las estrategias necesarias para el cumplimento de los ODS. La asignación de responsabilidades dentro de la estructura de gobierno para trabajar en este sentido, tanto en los Grupos de Alto Nivel (GAN), las distintas Unidades de la Administración General del Estado (AGE) así como la creación del Alto Comisionado para la Agenda 2030 en julio de 2018, suponen un paso importante en la gestión y coordinación de las acciones requeridas por la Agenda 2030.

El compromiso del estado español con el cumplimiento de los ODS hizo posible la creación de la Secretaría de Estados para la Agenda 2030 dedicada a la puesta en marcha y supervisión relativa a la implementación de las acciones contenidas en los ODS. Asimismo, podemos valorar positivamente la voluntad política de trabajar coordinadamente tanto en los distintos niveles de gobierno como con el resto de los sectores públicos y privados que conforman el país. Mediante las sesiones de diálogo propuestas por el gobierno, han hecho llegar sus propuestas, inquietudes, aportes y exigencias para mejorar tanto las condiciones de la sociedad española como la de los grupos vulnerables de terceros países. Fundamentalmente se valora la labor de las ONG's, ya que, al ser un sector muy profesionalizado, ha tomado el liderazgo en la ejecución y seguimiento de los ODS en el país. Las recomendaciones y propuestas hechas por el tercer sector, el sector empresarial, la academia y organizaciones de la sociedad civil, fueron claves para la presentación del Examen Nacional Voluntario (ENV). Es por ello que consideramos que la voluntad política y de diálogo que está teniendo el gobierno español, constituye una de las grandes fortalezas tanto a nivel nacional como internacional.

Para hacer posible el logro de los 17 objetivos y las 169 metas de la Agenda 2030 para el Desarrollo se requiere, además de la voluntad política, continuar trabajando y mejorando los programas y acciones que promueven un desarrollo sostenible en todo el mundo. Para ello se necesita de la disposición de los recursos físicos, económicos y tecnológicos para llevarlos a cabo. Consideramos que la promoción de una cooperación multilateral con la participación de todos los sectores de la sociedad, pueden ser una buena herramienta para avanzar hacia un desarrollo sostenible integral, sobre todo en medio de una crisis económica y sanitaria mundial. Por lo que se vislumbra viable dicho cumplimiento, siempre que se mantenga el compromiso político, económico y social de toda la sociedad internacional en su conjunto. 


\section{Referencias Bibliográficas}

AGNU, Asamblea General de Naciones Unidas (2015). Resolución aprobada por la Asamblea General el 25 de septiembre de 2015: Transformar nuestro mundo: la Agenda 2030 para el Desarrollo. A/RES/70/1, Septuagésimo período de sesiones. Nueva York, Estados Unidos, pp. 40

ARGUILÉS, J. M. (2014). “25 años de evaluación de la política española de cooperación internacional para el desarrollo" Revista de Evaluación de Programas y Políticas Públicas, UNED, Facultad de ciencias Económicas y Empresariales, № 3. $22-57$.

BOE (1998). Ley de Cooperación Internacional para el desarrollo, Nº 162, pp.

BOE (1998a). Real Decreto 23/1998, Ley de Cooperación Internacional para el Desarrollo, Núm. 162, pp. 22-56.

BONI, A. (2010). El sistema español de cooperación internacional al desarrollo, en La Cooperación Internacional para el Desarrollo, Capitulo III. Cuadernos de Cooperación para el Desarrollo. Núm. 1. Centro de Cooperación al Desarrollo, Editorial Universitat Politècnica de València.

CASCANTE, K. (2020). El desafío global de la covid-19 y la inerte cooperación española. Serie Documentos de Trabajo, Instituto Universitario de Desarrollo y Cooperación IUDC-UCM, Madrid, ISSN: 2253-8542.

CEPAL (2016). Agenda 2030 y los Objetivos de Desarrollo Sostenible. Una oportunidad para América Latina y el Caribe, Naciones Unidas y CEPAL, Santiago.

COLACRAI, M. (2010). "Los Países de Renta Media (PRM) latinoamericanos en el contexto de la Cooperación Española al Desarrollo. Claves para analizar el rol desempeñado por Argentina y Chile". Historia Actual Online, ISSN-e 1696-2060, No. 21, 2010, pp. 57-73. Recuperado de: https://dialnet.unirioja.es/servlet/articulo?codigo=3193706.

GOBIERNO DE ESPAÑA (2018). Informe de España para el Examen Nacional Voluntario 2018. Gobierno de España, Madrid.

GÓMEZ, M. (2010). El Sistema Español de Cooperación Internacional al Desarrollo, en La Cooperación Internacional para el Desarrollo, Capítulo III. Cuadernos de Cooperación para el Desarrollo, $\mathrm{N}^{\circ} 1$. Centro de Cooperación al Desarrollo, Editorial Universitat Politècnica de València. pp.77-89.

LAGARES, N. (2011). Cooperación al desarrollo y opinión pública. RIPS, ISSN 1577-239X. Vol. $\quad 10, \quad \mathrm{~N}^{\mathrm{O}} \quad 1, \quad$ pp. https://minerva.usc.es/xmlui/bitstream/handle/10347/8409/pg_069$\underline{084 \text { rips } 10 \_1 . p d f \text { ? sequence }=1 \& \text { isAllowed }=\mathrm{y}}$. 
OXFAM Intermón y UNICEF Comité Español (2015). España frente a los retos de la Agenda de Desarrollo Sostenible", Madrid, España.

\section{Cómo citar}

Verdiales Lopez, D. M. (2021). La Cooperación Internacional al Desarrollo española en el marco de la Agenda 2030 para el Desarrollo Sostenible. Revista de Integración y Cooperación Internacional, 32 (Ene-Jun), 42-57 